\title{
Qualidade sensorial de néctares de maracujás BRS Ouro Vermelho produzidos em diferentes sistemas de cultivo ${ }^{1}$
}

\author{
Juliana da Silva Quintiliano Rodrigues ${ }^{2}$, Lívia de Lacerda de Oliveira Pineli ${ }^{3}$, Nithyama Gouveia Rodrigues ${ }^{4}$, \\ Herbert Cavalcante de Lima ${ }^{5}$, Ana Maria Costa ${ }^{6}$, Carlos Henrique Osorio Silva ${ }^{7}$, \\ Nilton Tadeu Vilela Junqueira ${ }^{8}$, Marileusa D Chiarello $^{9}$
}

\section{RESUMO}

O objetivo deste trabalho foi avaliar o perfil sensorial e a aceitabilidade de néctares de maracujás obtidos de plantas submetidas a diferentes sistemas de produção, orgânico e convencional, com ou sem sombreamento pelo consórcio com mandioca. As amostras foram avaliadas por Análise Descritiva Quantitativa e por teste de aceitação com escala hedônica. Os dados do perfil descritivo e de aceitação foram analisados por Mapa de Preferência Externo, Análise de Variância e teste de comparação de médias de Fisher. Observou-se que os frutos que não foram submetidos ao sombreamento apresentaram néctares com perfil sensorial bastante semelhante e maior aceitação. Néctares de maracujá convencional não sombreado e orgânico não sombreado apresentaram correlação com os atributos aroma verde, homogeneidade e gosto ácido. As maiores diferenças na aceitação foram observadas entre as amostras convencional sombreada e orgânico não sombreada, com diferenças significativas nos atributos de cor, sabor e qualidade global. $\mathrm{O}$ Mapa de Preferência Externo apontou que a amostra de néctar convencional sombreado, com menor aceitação, foi correlacionada com os atributos fibrosidade e viscosidade.

Palavras-chave: maracujá, produção orgânica, sombreamento, aceitabilidade, perfil sensorial, Passiflora edulis.

\section{ABSTRACT \\ Sensory analysis of nectar of passion fruit cv. BRS Ouro Vermelho under different crop systems}

The objective of this study was to evaluate the sensory profile and acceptability of passion fruit nectar obtained from plants cultivated under different production systems: organic or conventional, with or without shading by intercropping with cassava. The samples were evaluated by Quantitative Descriptive Analysis and Acceptance Testing with hedonic scale. Data from the descriptive profile and acceptance were analyzed by External Preference Mapping, Analysis of Variance and the Fisher's LDS test. Fruits that were not subjected to shading produced nectars with very similar sensory profile and greater acceptance. Unshaded conventional and unshaded organic passion fruit nectars

\footnotetext{
Recebido para publicação em 26/12/2011 e aprovado em 03/06/2013.

'Projeto de graduação financiado pela Embrapa Cerrados, projeto PASSITEC.

${ }^{2}$ Nutricionista, Mestre. Departamento de Nutrição, Faculdade de Ciências da Saúde, Universidade de Brasília, 70910-900, Brasília, Distrito Federal, Brasil. ju_quntiliano@ hotmail.com ${ }^{3}$ Engenheira de Alimentos, PhD. Departamento de Nutrição, Faculdade de Ciências da Saúde, Universidade de Brasília, 70910-900, Brasília, Distrito Federal, Brasil. liviapineli@ unb.br (autora para correspondência).

${ }^{4}$ Nutricionista. Laboratório de Análise Sensorial, Universidade Católica de Brasília, 71966-700, Brasília, Distrito Federal, Brasil. nithyama@gmail.com

'Engenheiro-Agrônomo, PhD. Embrapa Cerrados, BR 020, Km18, Laboratório de Ciência de Alimentos, Caixa Postal 08223, 73310-970, Planaltina, Distrito Federal, Brasil. herbert@cpac.embrapa.br

${ }^{6}$ Engenheira-Agrônoma, PhD. Embrapa Cerrados, BR 020, Km18, Laboratório de Ciência de Alimentos, Caixa Postal 08223, 73310-9, Planaltina, Distrito Federal, Brasil. abarros@cpac.embrapa.br

${ }^{7}$ Engenheiro-Agrônomo, PhD. Departamento de Estatística, Universidade Federal de Viçosa, Campus Viçosa, Avenida Peter Henry Rolfs, s/n, 36570-00, Viçosa, Minas Gerais, Brasil. chos@dpi.ufv.br

${ }^{8}$ Engenheiro-Agrônomo, PhD. Embrapa Cerrados, BR 020, Km18, Laboratório de Ciência de Alimentos, Caixa Postal 08223, 73310-970, Planaltina, Distrito Federal, Brasil. junqueira@cpac.embrapa.br

${ }^{9}$ Farmacêutica, PhD. Laboratório de Análise Sensorial, Universidade Católica de Brasília, 71966-700, Brasília, Distrito Federal, Brasil. mdc@pos.ucb.br
} 
correlated with the attributes "green aroma", "homogeneity" and "sour taste". The greatest differences in acceptance were found between shaded conventional and unshaded organic samples for the attributes of color, flavor and overall quality. External preference mapping showed that the sample of nectar from shaded conventional passion fruit, with lower acceptance, was correlated with the attributes fibrousness and viscosity.

Key words: passion fruit, organic production, acceptability, sensory profile, Passiflora edulis.

\section{INTRODUÇÃO}

O termo maracujazeiro compreende várias espécies do gênero Passiflora L., da família Passifloraceae. O gênero Passiflora é constituído por aproximadamente 400 espécies, com mais de 150 delas nativas do Brasil (Bruckner \& Picanço, 2001). Várias são reconhecidas pelas propriedades funcionais de suas folhas, flores, raízes e frutos, recomendados para combater as mais diversas enfermidades, principalmente as do sistema nervoso central (Dhawan et al., 2004).

O suco de maracujá-azedo (Passiflora edulis va flavicarpa Deg) destaca-se entre os vários sucos de frutas tropicais consumidos nos mercados interno e externo, devido ao seu sabor exótico e intenso, forte aroma e alta acidez (Meletti \& Maia, 1999; Souza et al., 2002; Garruti, 1989; De Marchi et al., 2003). Segundo Deliza et al. (2005), sua polpa tem elevada intensidade do gosto ácido. Água e açúcar são, geralmente, adicionados para a obtenção de néctares.

O Brasil está entre os maiores produtores e consumidores de frutos de maracujá-azedo do mundo. No período de 1996 a 2003, a produção nacional passou de 409 mil para 485 mil toneladas (Gonçalves \& Souza, 2006), tendo alcançado a marca de 492 mil toneladas em 2005 (Pires, 2007), 664 mil em 2007 (Lima, 2009) e saltando para 920 mil em 2010 (IBGE, 2012), após a introdução de variedades melhoradas e tecnologias para a produção desenvolvidas pela Embrapa.

As variedades de maracujás e os sistemas de produção podem afetar as propriedades físicas e físico-químicas dos frutos (Borguini \& Torres, 2006; Costa et al., 2008). Estas propriedades são importantes para a aceitação comercial dos frutos de maracujazeiros.

O híbrido de maracujazeiro-azedo BRS Ouro Vermelho é uma variedade lançada pela Embrapa Cerrados em 2008 com excelente produtividade e maior tolerância às principais doenças que afetam a cultura de maracujá no Brasil (Gama, 2008). Pode ser produzido em sistemas convencional e orgânico, em consórcio com outras culturas sem perda das qualidades físicas e fisico-química dos frutos (Costa et al., 2008).
Quando o fruto é exposto à radiação solar, podem ocorrer manchas na casca, indesejáveis na comercialização. $\mathrm{O}$ sistema de produção tipo sombreamento é feito em consórcio com a cultura de mandioca, uma das mais tradicionais no Brasil. Além de gerar sombreamento adequado para o maracujá, a mandioca é fonte de alimentação e de geração de renda suplementar ao agricultor. Entretanto, o sombreamento não é obrigatório, podendo o maracujá ser produzido em pleno sol, sem comprometimento da qualidade da polpa (Costa et al., 2008).

O cultivo orgânico não utiliza agroquímicos, aproveita resíduos orgânicos, realiza rotação e consórcios com diferentes culturas para melhoria da qualidade do solo e controle de doenças (Guadagnin et al., 2005). Apresenta vantagem em relação ao sistema convencional por causa do menor impacto negativo ao meio ambiente (Guadagnin et al., 2005). Entretanto, a produtividade normalmente é menor, o que torna o alimento mais caro.

Segundo Darolt (2003), os estudos da qualidade sensorial de produtos orgânicos que avaliam sabor, aroma, acidez, entre outros atributos, são pouco conclusivos quando comparados aos produtos de cultivo convencional. Esse afirma existirem dificuldades na pesquisa comparativa pela falta de controle de outras variáveis, como a variedade utilizada, o tipo de solo e clima, o ano climático e o modo de produção. Cita, ainda, que nas pesquisas que controlaram a maior parte dessas variáveis observou-se ligeira superioridade do produto orgânico, mas não houve a comprovação dos dados analisados com base em procedimentos estatísticos adequados. Malta et al. (2008) observaram que houve diferenças significativas entre os atributos sensoriais do café orgânico e do café convencional por causa da utilização de adubos orgânicos.

Segundo Monteleone et al. (1997), estudar as relações entre os atributos sensoriais e a aceitação de um produto requer a aplicação de técnicas estatísticas adequadas. Os resultados podem ser úteis para o estabelecimento de controle de qualidade eficiente para formular ou aperfeiçoar produtos, assim como para avaliar potenciais oportunidades de mercado. 
Dentre os métodos sensoriais analíticos utilizados em alimentos, a Análise Descritiva Quantitativa (ADQ) proporciona uma descrição das propriedades sensoriais de um produto de forma simples e é muito utilizada para a caracterização sensorial de atributos importantes (Stone et al., 1998). Entretanto, a ADQ não permite a análise do relacionamento entre preferências e atributos sensoriais. Outros testes úteis no campo da análise sensorial são os afetivos, que geralmente vêm em sequência aos testes descritivos. Os afetivos medem o grau de gostar ou desgostar de determinado produto, ou ainda a preferência que o consumidor assume sobre um produto com relação a outro. Esses testes podem fornecer informações complementares aos resultados obtidos pela ADQ (Stone \& Sidel, 1985).

A relação entre a aceitabilidade e o perfil descritivo de produtos pode ser obtida por meio de mapas de preferência. O mapa de preferência, segundo MacFie \& Thomson (1988), é essencialmente uma representação gráfica multidimensional das diferenças de aceitação entre as amostras, que permite a identificação de cada indivíduo e suas preferências em relação às amostras analisadas.

O objetivo do presente estudo foi comparar o perfil sensorial e a aceitabilidade de néctares de maracujás BRS Ouro Vermelho, produzidos nos sistemas orgânico e convencional, submetidos ou não ao consórcio com mandioca.

\section{MATERIAL E MÉTODOS}

O campo de produção de frutos do maracujá híbrido BRS Ouro Vermelho foi implementado na área experimental do Núcleo Rural Jardim 2, Colônia Agrícola Ipapety, DF, em novembro de 2006. Os sistemas de produção empregados foram cultivos orgânico e convencional, combinados ou não com sombreamento por consórcio com mandioca (Tabela 1). O delineamento experimental foi em blocos completos casualizados, com quatro repetições por tratamento, sendo cada unidade experimental formada por uma parcela com 50 plantas.

Os frutos foram colhidos na safra de maio de 2008. As respectivas polpas foram obtidas com o auxílio de despolpadeira, conforme o procedimento operacional padrão da Embrapa Cerrados, e congeladas a $-20^{\circ} \mathrm{C}$.

As amostras das polpas foram enviadas ao Laboratório de Ciências e Tecnologia dos Alimentos da Universi- dade Católica de Brasília (UCB), devidamente congeladas e embaladas, transportadas em caixas de isopor.

As polpas foram diluídas na proporção de uma parte de polpa para seis partes de água, acrescidas de $8 \%$ de açúcar e liquidificadas por um minuto. O teor de sólidos solúveis final foi de $10^{\circ} \mathrm{Brix}$. As amostras foram porcionadas em $30 \mathrm{~mL}$ e servidas aos julgadores à temperatura ambiente em copos descartáveis transparentes de $50 \mathrm{~mL}$, codificadas com três dígitos aleatórios. Foi servida água filtrada entre as amostras para eliminação do sabor residual.

\section{Análise Descritiva Quantitativa}

Uma ficha de recrutamento foi distribuída a alunos, funcionários e professores da Universidade Católica de Brasília, sem nenhum critério pré-estabelecido, para que os interessados anotassem informações sobre disponibilidade de horários para as sessões de treinamento, condições de saúde, habilidade com termos descritivos e sobre a utilização de escalas de intensidade.

Na seleção dos provadores todos os candidatos submeteram-se a uma sequência de 12 testes triangulares com amostras de néctares comerciais de maracujá com e sem a adição de $0,05 \%$ (p/v) de ácido cítrico. Cada candidato realizou dois testes por dia, e foram selecionados inicialmente 12 provadores que responderam corretamente a, pelo menos, $50 \%$ dos testes.

No levantamento dos descritores sensoriais para néctares de maracujá foram utilizadas como referência um néctar preparado a partir de uma marca comercial de suco integral, uma marca comercial de néctar de maracujá, além de polpas congeladas de maracujás de sete diferentes espécies de passifloras, obtidas em campos experimentais da Embrapa Cerrados.

A determinação da terminologia descritiva foi realizada pelo Método de Rede com a apresentação aos provadores das amostras aos pares, em todas as combinações possíveis (Meilgaard et al., 1987), sendo-lhes solicitado que anotassem individualmente as similaridades e diferenças entre cada par de amostra com relação à aparência, ao sabor, aroma e à textura/consistência. Ao final das anotações individuais, o grupo foi encaminhado para a mesa redonda, e de forma consensual chegou aos termos que melhor descreveram as diferenças e similaridades entre as amostras.

Tabela 1. Códigos das amostras de polpas referentes aos tratamentos utilizados no cultivo das Passifloras sp.

\begin{tabular}{ll}
\hline Códigos & Sistema de cultivo (Tratamentos) \\
\hline CS & Convencional Sombreado, com mandioca plantada ao lado da espaldeira \\
CNS & Convencional Não sombreado, sem consórcio com mandioca. \\
OS & Orgânico Sombreado, com mandioca plantada ao lado da espaldeira. \\
ONS & Orgânico Não sombreado, sem consórcio com mandioca. \\
\hline
\end{tabular}


Em sessões posteriores, o grupo elaborou definições para os termos descritivos escolhidos e estabeleceu amostras-referência para os extremos da escala de intensidade (escala não estruturada de $9 \mathrm{~cm}$ ) para cada um dos termos. Ao final, foi consolidada uma lista com 12 descritores, com as respectivas referências (Tabela 2). Após oito sessões de treinamento, os provadores foram submetidos a testes de validação, em que se avaliaram quatro amostras de néctar de maracujá codificadas. Cada amostra foi avaliada nove vezes (sessões) de forma monádica e em ordem aleatorizada, com os códigos alterados a cada sessão.

Com os dados dos testes de validação efetuou-se, para cada atributo e provador, uma análise de variância (ANOVA) com duas fontes de variação: amostras, com três graus de liberdade (GL) e repetição com 8 GL. Os provadores foram selecionados com base em sua capacidade discriminatória (valor de $\mathrm{p}$ do teste F para amostra $\leq 0,50$ ) e repetibilidade (valor de $\mathrm{p}$ do teste $\mathrm{F}$ para repetição >0,05) e concordância das médias com a média

Tabela 2. Definição dos termos descritivos para espécies de Passifloras sp.

\begin{tabular}{|c|c|c|}
\hline Atributos & Definições & Referências \\
\hline Cor amarelo-alaranjada & $\begin{array}{l}\text { Tonalidade característica, que varia de } \\
\text { amarelo-clara a forte, podendo-se } \\
\text { aproximar do alaranjado }\end{array}$ & $\begin{array}{l}\text { Fraco: Polpa nítida (diluição 1:6) } \\
\text { Forte: Suco Jandaia }{ }^{\circledR} \text { (sem diluição) }\end{array}$ \\
\hline Opacidade & $\begin{array}{l}\text { É definido como ausência de translucidez, } \\
\text { opacidade ou aspecto leitoso }\end{array}$ & $\begin{array}{l}\text { Fraco: Néctar Camp® } \\
\text { Forte: Suco Parmalat }{ }^{\circledR} \text { (sem diluição) }\end{array}$ \\
\hline Homogeneidade & Definida pela ausência de separação de fases & $\begin{array}{l}\text { Fraco: Suco Jandaia }{ }^{\circledR} \text { (diluição 1:4) } \\
\text { Forte: Suco Maguary® (sem diluição) }\end{array}$ \\
\hline $\begin{array}{l}\text { Aroma característico } \\
\text { de maracujá }\end{array}$ & $\begin{array}{l}\text { Resultante da combinação de substâncias } \\
\text { presentes no fruto, o faz ser identificado } \\
\text { como maracujá }\end{array}$ & $\begin{array}{l}\text { Fraco: Maracujá comercial in natura (diluição1:2) } \\
\text { Forte: polpa nítida (diluição 1:2) }\end{array}$ \\
\hline Aroma de deteriorado & $\begin{array}{l}\text { Atributo relacionado a cheiro de passado, } \\
\text { estragado, em apodrecimento }\end{array}$ & $\begin{array}{l}\text { Fraco: Maracujá in natura (diluição1:6) } \\
\text { Forte: Polpa alata (diluição 1:1) }\end{array}$ \\
\hline Aroma verde & $\begin{array}{l}\text { Atributo relacionado com cheiro de casca } \\
\text { de maracujá ou de maracujá verde }\end{array}$ & $\begin{array}{l}\text { Fraco: Maracujá in natura (diluição 1:2) } \\
\text { Forte: Polpa tenuifila (diluição 1:1) }\end{array}$ \\
\hline $\begin{array}{l}\text { Sabor característico } \\
\text { de maracujá }\end{array}$ & $\begin{array}{l}\text { Resultante da combinação de substâncias } \\
\text { presentes no fruto, o faz ser identificado } \\
\text { como maracujá }\end{array}$ & $\begin{array}{l}\text { Fraco: Maracujá in natura (diluição 1:12 com } 8 \% \\
\text { de açúcar) } \\
\text { Forte: Maracujá in natura (diluição 1:4 com } 8 \% \text { de } \\
\text { açúcar) }\end{array}$ \\
\hline
\end{tabular}

Fraco: Néctar com suco de maracujá Maguary

(diluição de 1:5 com $8 \%$ de sacarose)

Gosto ácido

Azedo, que contém ácidos orgânicos

Forte: néctar com suco de maracujá Maguary

(diluição 1:2 com 8\% de sacarose e 10\% de solução de ácido cítrico $0,25 \%$ )

Fraco: Suco Maguary® (diluição 1:4 com 8\% de açúcar $+6 \%$ de solução de ácido tânico)

Adstringência

Sensação percebida na boca, que "aperta" ou "trava".

Forte: Suco Maguary® (diluição 1:4 com 8\% de açúcar $+0,5 \%$ de solução de ácido tânico)

Fraco: Suco Maguary ${ }^{\circledR}$ (diluição 1:4 com 6\% de açúcar)

Gosto doce Relativo à presença de açúcares

Forte: Suco Maguary® (diluição 1:4 com 11\% de açúcar)

Fraco: Polpa tenuifila (diluição 1:20 com $8 \%$ de açúcar)

Fibrosidade quando, na prova da amostra, a textura do Forte: Polpa tenuifila (diluição 1:3 com $8 \%$ de néctar não é lisa e sim fibrosa açúcar)

Fraco: Néctar Camp®

Viscosidade

Relativa à consistência grossa ou encorpada, não rala, não fluida, da amostra

Forte: Suco Maguary® (diluição 1:3 com 8\% de açúcar)

Rev. Ceres, Viçosa, v. 60, n.5, p. 595-602, set/out, 2013 
da equipe para cada atributo (diferença não significativa, p > 0,05, pelo teste LSD de Fisher), conforme sugerido por Damásio \& Costell (1991).

Os oito provadores selecionados avaliaram individualmente as quatro amostras de néctar de maracujá BRS Ouro Vermelho, em cultivos orgânico e convencional, com e sem sombreamento, em duas repetições. A ordem de apresentação das amostras seguiu um esquema em blocos completos e aleatorizados e foram servidas de forma monádica (Stone \& Sidel, 2004). Os resultados obtidos na análise sensorial foram avaliados por análise de variância, com comparações entre médias pelo teste LSD, FisherLeast Significant Difference e Mapa de Preferência Externo, sendo a análise por meio da Análise de Componentes Principais. Adotou-se 5\% como nível de significância nas análises.

\section{Teste de aceitação}

Para a análise das quatro amostras de néctar de maracujás, foram recrutados 102 consumidores entre os estudantes e funcionários da Universidade Católica de Brasília (UCB) que declararam gostar de refrescos e néctares de maracujá. O teste foi conduzido em sessão única no Laboratório de Análise Sensorial da UCB, em cabines individuais sob luz branca.

As amostras foram identificadas com um código de três dígitos, servidas em ordem aleatorizada para cada provador. Entre as amostras foi requisitado o consumo de água, para evitar a fadiga sensorial. A avaliação foi realizada por escala hedônica estruturada de nove pontos, sendo nota 1 correspondente a "desgostei muitíssimo" e 9 a "gostei muitíssimo", com avaliação estratificada para aparência, aroma, sabor, textura e qualidade global.

Os dados dos testes de aceitação foram avaliados por ANOVA, com as seguintes fontes de variação: tratamentos (3 GL), provadores (101 GL) e resíduo (303 GL), seguida por comparações entre médias de atributos para as amostras de polpa pelo teste de Tukey a $5 \%$.

Os valores de aceitação também foram utilizados para elaboração do Mapa de Preferência Externo. Ele relaciona os dados de aceitação de cada consumidor com o espaço amostral descritivo (ACP), constituído a partir dos dados resultantes de uma análise descritiva, como a ADQ (Addinsoft, 2011). Aliando-se ao teste de médias, o mapa de preferências pode explicar as preferências dos consumidores de forma mais abrangente e com informações mais detalhadas. Esse mapa foi gerado no programa XLSTAT (Addinsoft, 2011), licenciado para a UnB em 2009.

\section{RESULTADOS E DISCUSSÃO}

Os perfis descritivos dos néctares de maracujás orgânicos e convencionais, com e sem sombreamento pela cultura da mandioca, foram comparados (Tabela 3 ).
Para os atributos opacidade e gosto doce não foram observadas intensidades estatisticamente diferentes ( $\mathrm{p}<$ $0,05)$ entre os néctares avaliados.

Para cor amarela as médias ficaram próximas, variando entre 4,68 e 5,94. Estatisticamente, néctar de maracujá ONS apresentou maior intensidade da cor em relação aos demais tratamentos.

O néctar de maracujá ONS foi o que teve menores intensidades de adstringência, sabor característico e gosto ácido, sendo diferenciado das demais amostras por esses atributos.

Os valores de homogeneidade foram baixos para todos os néctares, indicando intensa separação de fases nas amostras. As amostras de néctares de maracujá ONS e CS foram ainda menos homogêneas que as demais. A separação de fases é comum em néctares de maracujá elaborados com polpa não pasteurizada. A atividade enzimática pode acarretar quebra da estrutura das pectinas, desestabilizando o sistema. De acordo com Iaderoza \& Draetta (1991), a pectinametilesterase é encontrada com frequência em frutos destinados à produção de sucos, principalmente os de maracujá. Segundo Lafuente (1985), a pectina é o estabilizador coloidal natural de sucos, conferindo-lhes viscosidade e consistência. Quando esse coloide se degrada pela ação da pectinametilesterase, o suco clarifica e adquire aspecto aquoso por causa da rápida sedimentação do material em suspensão. Logo, maior perda de homogeneidade pode estar relacionada a uma maior atividade de enzimas pécticas.

Outra característica relevante de textura é a viscosidade. Para os tratamentos avaliados, observou-se que néctares de maracujás cultivados no sistema convencional foram mais viscosos do que aqueles feitos com os maracujás produzidos em sistema orgânico.

O néctar de maracujá CS diferenciou-se das outras amostras pela maior fibrosidade. Porém, as notas médias para esta característica foram baixas para todos os tratamentos. Isso indica que os néctares apresentaram textura lisa, não sendo percebidas muitas partículas durante sua degustação.

De acordo com Narain (2004), o aroma verde, observado em algumas espécies de maracujás, é atribuído à presença de sulfuratos. Desses, o 3-metiltio-hexanol possui nota 'verde' sulfurosa ou gordurosa, associado a uma mistura de (Z)-e (E)-2-metil-4-propil-oxatianos, os quais possuem cheiro 'verde' e 'pouco queimado', contribuindo para o aroma característico de maracujá. O aroma verde foi detectado pela equipe de provadores em baixa intensidade nos tratamentos avaliados, tendo a amostra CNS obtido maior média para este atributo.

Não houve diferença na aceitação dos néctares em relação ao aroma e à textura (Tabela 4). Para cor, sabor e qualidade global, houve diferença na aceitabilidade entre 
os néctares de maracujá ONS e CS, tendo o primeiro obtido maiores notas hedônicas. Cabe observar que todas as amostras obtiveram nota média de aceitação sempre maior que 6, referente ao termo hedônico "gostei ligeiramente". Uma limitação relacionada à análise das médias de aceitação é que as preferências individuais dos provadores ou de segmentos de provadores não são identificadas.

Por esse motivo, a elaboração dos mapas de preferência é importante ferramenta para melhor visualização do comportamento dos consumidores em relação a cada uma das amostras.

No mapa de preferência externo, apresentado na Figura 1a, os dados de cada provador foram representados com um ponto no espaço. Indivíduos que tiveram opinião semelhante sobre os produtos estão próximos entre si, e a concentração na região da amostra indica maior ou menor aceitação. Além disso, pelo gráfico de contorno, é possível visualizar quantos provadores apresentam aceitação acima da média em dada região do mapa, o que é indicado por meio de cores.

De acordo com a Figura 1a, pôde-se verificar que as amostras ONS e CNS tiveram maior aceitação, pois se situaram na região em cor alaranjada, indicando que 60 a $70 \%$ dos julgadores apresentam aceitação acima da média para esses tratamentos. A amostra OS teve aceitação intermediária, posicionando na região em cor verde-escura (representado 40 a 50\% de aceitação acima da média), enquanto a amostra CS situou-se na região em cor verdeclara (representando 30 a $40 \%$ de provadores com aceitação acima da média).

AACP procura uma combinação linear das variáveis, a fim de maximizar a variância total explicada. Se as variáveis são altamente correlacionadas, elas serão combinadas em um componente que irá explicar a maior quantidade de variância da amostra (CP1). A segunda componente (CP2) explica a segunda maior quantidade de variância e não será correlacionada com o primeiro componente (Favero et al., 2009).

Os dois primeiros componentes principais da ACP com os dados sensoriais da ADQ (Figura 1b) explicaram aproximadamente $82,21 \%$ da variação entre as amostras (Figura 1b).

Pôde-se observar que os néctares ONS e CNS apresentaram maior correlação com os atributos aroma verde, homogeneidade e gosto ácido, o que sugere que essas características podem ter influenciado para a maior aceitação dessas amostras.

O néctar OS, que teve aceitação intermediária, foi correlacionado com os atributos cor amarela e aroma ca-

Tabela 3. Médias $(n=102)$ dos atributos sensoriais avaliados nas amostras de néctar de maracujá

\begin{tabular}{|c|c|c|c|c|}
\hline & $\begin{array}{c}\text { Convencional } \\
\text { Sombreado (CS) }\end{array}$ & $\begin{array}{c}\text { Convencional } \\
\text { Não sombreado(CNS) }\end{array}$ & $\begin{array}{c}\text { Orgânico Sombreado } \\
\text { (OS) }\end{array}$ & $\begin{array}{c}\text { Orgânico } \\
\text { Não sombreado (ONS) }\end{array}$ \\
\hline Cor amarela & $5,01^{\mathrm{b}}$ & $4,98^{b}$ & $4,68^{b}$ & $5,94^{\mathrm{a}}$ \\
\hline Opacidade & $3,44^{\mathrm{a}}$ & $4,05^{\mathrm{a}}$ & $3,10^{\mathrm{a}}$ & $3,41^{\mathrm{a}}$ \\
\hline Homogeneidade & $0,30^{\mathrm{b}}$ & $0,80^{\mathrm{a}}$ & $0,70^{\mathrm{a}}$ & $0,13^{\mathrm{b}}$ \\
\hline Aroma característico & $8,02^{\mathrm{a}}$ & $5,94^{\mathrm{b}}$ & $6,51^{\mathrm{b}}$ & $7,68^{\mathrm{a}}$ \\
\hline Aroma deteriorado & $0,14^{\mathrm{ab}}$ & $0,13^{\mathrm{ab}}$ & $0,29^{\mathrm{a}}$ & $0,05^{\mathrm{b}}$ \\
\hline Aroma verde & $0,08^{\mathrm{b}}$ & $0,22^{\mathrm{a}}$ & $0,11^{\mathrm{ab}}$ & $0,08^{\mathrm{b}}$ \\
\hline Gosto ácido & $4,31^{\mathrm{a}}$ & $5,50^{\mathrm{a}}$ & $4,60^{\mathrm{a}}$ & $0,70^{\mathrm{b}}$ \\
\hline Sabor característico & $7,70^{\mathrm{a}}$ & $7,60^{\mathrm{a}}$ & $7,10^{\mathrm{a}}$ & $6,40^{\mathrm{b}}$ \\
\hline Adstringência & $5,80^{\mathrm{a}}$ & $5,60^{\mathrm{ab}}$ & $4,50^{\mathrm{b}}$ & $1,20^{\mathrm{c}}$ \\
\hline Gosto doce & $5,20^{\mathrm{a}}$ & $4,90^{\mathrm{a}}$ & $4,70^{\mathrm{a}}$ & $4,30^{\mathrm{a}}$ \\
\hline Fibrosidade & $0,60^{\mathrm{a}}$ & $0,15^{\mathrm{b}}$ & $0,10^{\mathrm{b}}$ & $0,20^{\mathrm{b}}$ \\
\hline Viscosidade & $5,30^{\mathrm{a}}$ & $4,20^{\mathrm{a}}$ & $1,90^{\mathrm{b}}$ & $1,70^{\mathrm{b}}$ \\
\hline
\end{tabular}

Médias seguidas por pelo menos uma letra igual, na mesma linha, indicam que as amostras não diferem entre si pelo Teste LSD de Fisher $(\mathrm{p}>0,05)$.

Tabela 4. Médias de aceitação das amostras de maracujá $(\mathrm{n}=102)$

\begin{tabular}{|c|c|c|c|c|}
\hline & OS & CNS & $\mathrm{CS}$ & ONS \\
\hline Cor & $7,35^{\mathrm{ab}}$ & $7,06^{\mathrm{ab}}$ & $6,95^{\mathrm{b}}$ & $7,47^{\mathrm{a}}$ \\
\hline Aroma & $6,79^{a}$ & $6,64^{\mathrm{a}}$ & $6,42^{\mathrm{a}}$ & $6,70^{\mathrm{a}}$ \\
\hline Sabor & $6,84^{\mathrm{ab}}$ & $6,81^{\mathrm{ab}}$ & $6,39^{\mathrm{b}}$ & $6,99^{\mathrm{a}}$ \\
\hline Textura & $6,82^{\mathrm{a}}$ & $6,99^{\mathrm{a}}$ & $6,58^{\mathrm{a}}$ & $6,86^{\mathrm{a}}$ \\
\hline Qualidade global & $7,0^{\mathrm{ab}}$ & $7,05^{\mathrm{ab}}$ & $6,67^{b}$ & $7,23^{\mathrm{a}}$ \\
\hline
\end{tabular}

Médias na mesma linha, seguidas por pelo menos uma letra igual, indica que as amostras não diferem entre si pelo Teste LSD de Fisher $(\mathrm{p}>0,05)$.

Rev. Ceres, Viçosa, v. 60, n.5, p. 595-602, set/out, 2013 
racterístico. Já a amostra de menor aceitação, CS, foi correlacionada com os atributos fibrosidade e viscosidade, o que pode ter influenciado na baixa aceitação.

Levando em consideração o sistema de produção, no cultivo convencional o sombreamento aumentou a correlação com a fibrosidade, o aroma característico e a vis- cosidade e o gosto doce e diminuiu com a homogeneidade e o aroma verde.

Já no cultivo orgânico, o sistema de sombreamento aumentou a cor e o aroma característico e diminuiu as demais propriedades, fazendo com que o néctar ONS ficasse muito semelhante com o néctar CNS.

Biplot (axes F1 and F2: 82,21 \%)
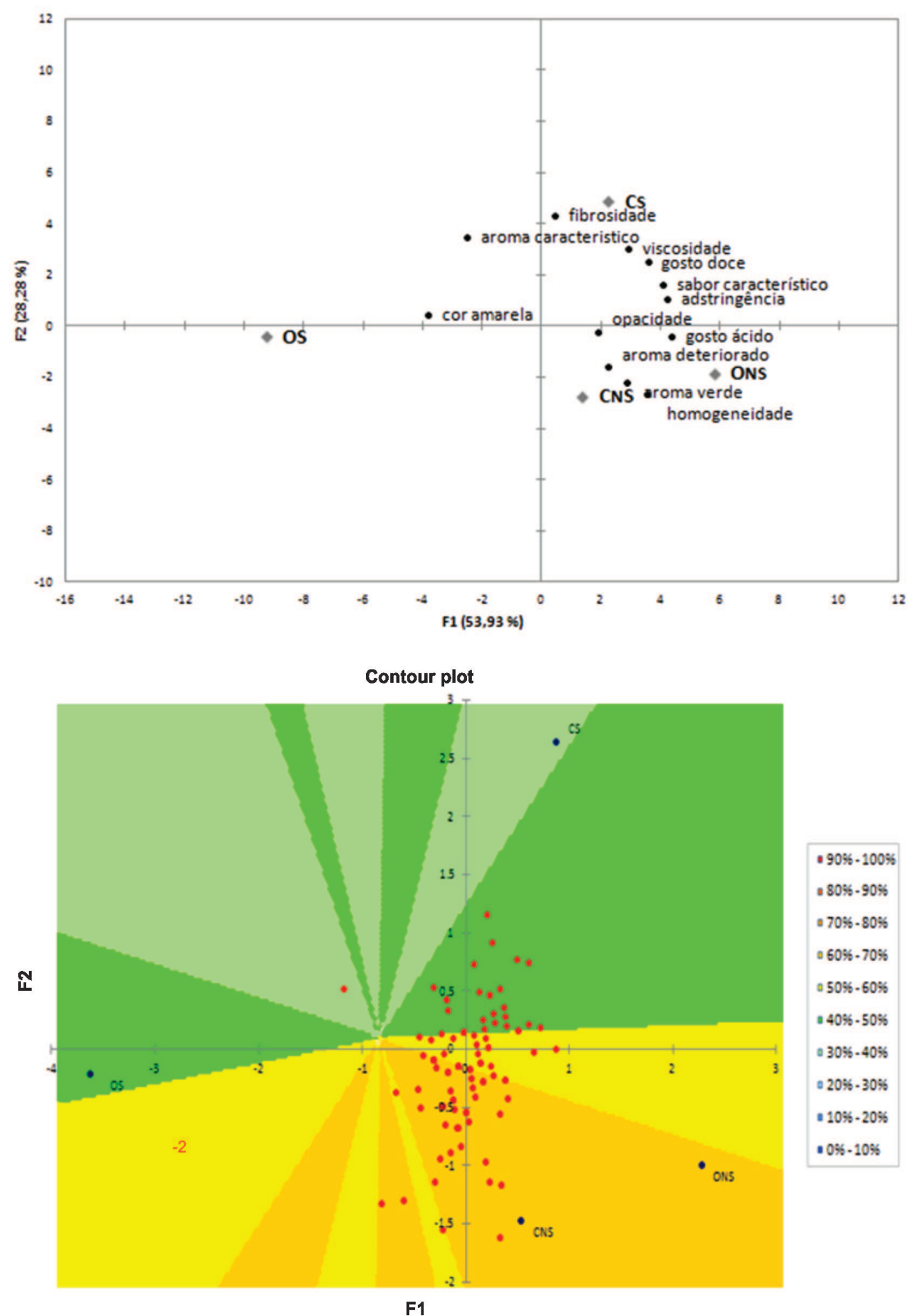

Figura 1. Mapa de Preferência Externo. (a) Análise dos componentes principais (ACP); (b) Gráfico de contorno. Tratamentos são: CNS - maracujá convencional não sombreado; CS - maracujá convencional sombreado; OS - maracujá orgânico sombreado; e NOS maracujá orgânico não sombreado. 


\section{CONCLUSÕES}

Houve efeito do sistema de cultivo e do sombreamento na aceitação e nas características sensoriais de néctares de maracujá BRS Ouro Vermelho. As maiores diferenças foram observadas entre as amostra CS e ONS, que revelaram diferenças significativas nos atributos de cor, sabor e qualidade global, sendo a última a mais aceita.

O sombreamento afetou de forma diferente os frutos cultivados nos sistemas orgânico e convencional, porém foi verificado que os frutos que não foram submetidos ao sombreamento, ONS e CNS, tiveram melhor aceitação pelos provadores.

\section{AGRADECIMENTOS}

À Embrapa Cerrados, pelo apoio com o material cedido para análises e auxílio financeiro; ao CNPq, pela bolsa de iniciação científica, à Juliana da Silva Quintiliano Rodrigues; e à PRPGP-UCB, pelo apoio financeiro.

\section{REFERÊNCIAS}

Addinsoft (2011) Xlstat version 2011.4.02. Software e Guia do Usuário. Disponível em <http://www.xlstat.com>. Acesso em: 19 junho 2012.

Borguini RG \& Torres EAFS (2006) Alimentos Orgânicos: Qualidade nutritiva e segurança do alimento. Segurança alimentar e Nutricional, 13:64-75.

Bruckner CH \& Picanço MC (2001) Maracujá: tecnologia de produção, pós-colheita, agroindústria e mercado. Porto Alegre, Cinco Continentes. 472p.

Costa AM, Cohen KO, Tupinambá DD, Brandão LS, Silva DC \& Junqueira NTV (2008) Propriedades físicas e físico-químicas de maracujás cultivados nos sistemas orgânico e convencional em consórcio com mandioca. Planaltina, DF: Embrapa Cerrados. 6p. (Comunicado Técnico, 158).

Damásio MH \& Costell E (1991) Analisis sensorial descriptiva: generación de descriptores y seleccion de catadores. Revista Agroquímica y Technologia de Alimentos, 31:165-178.

Darolt MR (2003) Comparação da Qualidade do Alimento Orgânico com o convencional. In: Strigheta PC \& Muniz JN (Eds.) Alimentos Orgânicos: Produção, Tecnologia e Certificação. Viçosa, Universidade Federal de Viçosa. p.289-312.

Deliza R, MacFie HJH \& Hedderley D (2005) The consumer sensory perception of passion-fruit juice using free-choice profiling. Journal of Sensory Studies, 20:17-27.

De Marchi R, Monteiro M \& Cardello HMAB (2003) Avaliação da vida-de- prateleira de um isotônico natural de maracujá (Passiflora edulis Sims. f. flavicarpa Deg.). Brazilian Journal of Food and Technology, 6:291-300.

Dhawan K, Dhawan S \& Sharma A (2004) Passiflora: a review update. Journal of Ethnopharmacology, 94, 01-23.

Gama L (2008) Agrosoft Brasil: Embrapa lança novos híbridos de maracujazeiro-azedo. Disponível em <http://www.agrosoft.org.br/ agropag/100840.htm>. Acessado em: 07 de março de 2010.

Garruti DS (1989) Contribuição ao estudo da estabilização física do suco de maracujá integral (Passiflora edulis f. flavicarpa) Dissertação de Mestrado. Universidade Estadual de Campinas, Campinas. $198 \mathrm{p}$.
Gonçalves JS \& Souza SAM (2006) Fruta da Paixão: panorama econômico do maracujá no Brasil. Informações Econômicas, 36:29-36.

Guadagnin SG, Rath S \& Reyes FGR (2005) Evaluation of the nitrate content in leaf vegetables produced through different agricultural systems. Food Additives and Contaminants, 22:1203-1208.

Favero LP, Belfiore P, Silva FL \& Chan BL (2009) Análise de dados. Modelagem multivariada para tomada de decisões. Rio de Janeiro, Elsevier. 544p.

Iaderoza M \& Draetta IS (1991) Ênzimos e pigmentos: Influências e alterações durante o processamento. In: Soler MP (Ed.) Industrialização de frutas. Campinas, ITAL. p.17-31. (Manual Técnico, 8).

IBGE - Instituto Brasileiro de Geografia e Estatística. Lavoura permanente - 2011 (2012). Maracujá: Área destinada à colheita. Disponível em: <http://www.ibge.gov.br/>. Acessado em: 08 de abril de 2012

Lafuente B (1985) Factores que afectan a la calidad y estabilidad del zumo de naranja semielaborado. Revista Agroquímica y Tecnología de Alimentos, 25:334-354

Lima CA (2009) Otimização de métodos de propagação do maracujazeiro via estaquia e enxertia. Dissertação de Mestrado. Universidade de Brasília, Brasília. 105p.

MacFie HJH \& Thomson DMH (1988) Preference Mapping and Multidimensional Scaling. In: Piggot JR (Ed.) Sensory Analysis of Foods. $2^{\text {nd }}$ ed. London, Elsevier. 389p.

Meletti LMM \& Maia ML (1999) Maracujá: produção e comercialização. Campinas, Instituto Agronômico. 62p. (Boletim Técnico, 181).

Malta MR, Pereira RGFA, Chagas SJR \& Ferreira DF (2008) Qualidade sensorial de café de lavouras em conversão para o sistema de produção orgânico. Tecnologia pós-colheita. . In: $5^{\circ}$ Simpósio de PESQUISA DOS Cafés do Brasil, Brasília. Anais, D.F.: Embrapa - Café. CD-ROM.

Meilgaard M, Civille GV \& Carr BT (1987) Sensory evaluation techniques. Florida, CRC Press. 158p.

Monteleone E, Carlucci A, Caporale G \& Pagliarini E (1997) Use of slope analysis to characterize preference for virgin olive oil. Italian Journal of Food Science, 9:133-140.

Narain N (2004) Aroma de Frutas Tropicais: III. Maracujá e Cajá no livro: Aromas e Sabor de Alimentos: Temas Atuais. In: Franco MRB (Ed.) Aroma e Sabor de Alimentos: Temas Atuais. São Paulo, Livraria Varela. p.75-86.

Pires MC (2007) Propagação de maracujazeiro por estaquia e enxertia em estacas enraizadas. Dissertação de Mestrado. Universidade de Brasília, Brasília. 86p.

Souza JS, Cardoso CEL, Folegatti MIS \& Matsuura FCAU (2002) Mercado Mundial. In: Maracujá pós-colheita. Brasília, Embrapa Informação Tecnológica. p.09-12.

Stone H, Sidel JL, Olivers S, Woolsey A \& Singleton C (1998) Sensory evaluation by quantitative descriptive analysis. Food technology, 52:48-52.

Stone H \& Sidel JL (1985) Descriptive analysis. In: Stone H \& Sidel JL (Eds.) Sensory evaluation Practices. London, Academic Press. p.311.

Stone H \& Sidel JL (2004) Sensory Evolution Practices. San Diego, Academic Press. p.308.

Rev. Ceres, Viçosa, v. 60, n.5, p. 595-602, set/out, 2013 